\title{
Modeling, Synthesis, and Characterization of Thin Film Copper Oxide for Solar Cells
}

\author{
Davis S. Darvish (ddarvish@caltech.edu), Harry A. Atwater (haa@caltech.edu) \\ Califomia Institute of Technology, Pasadena, CA, USA
}

\begin{abstract}
The modeling, growth, and characterization of Copper Oxide thin films for solar cell applications are reported. $\mathrm{Cu}_{2} \mathrm{O}$ has several attractive properties which include its direct band gap $(\mathrm{Eg}=2.17 \mathrm{eV})$ for use in photoelectrolysis of water and use in tandem multi-junction cells. Detailed balance calculations predict efficiencies on the order of $20 \%$ while $\mathrm{Cu}_{2} \mathrm{O}$ cells have yet to even pass $2 \%$ efficiency. The device physics model reveals that defects, particularly at the heterojunction interface, are the main reason for lowered efficiencies. Epitaxial $\mathrm{Cu}_{2} \mathrm{O}(100)$ thin films on $\mathrm{MgO}$ are fabricated using RF Oxygen plasma MBE. The films are quite smooth and showed mobilites in the range of $10-100 \mathrm{~cm}^{2} N^{*} \mathrm{sec}$ and carrier concentrations in the range of $10^{14}-10^{17}$. Finally, the epitaxial growth of $\mathrm{Cu}_{2} \mathrm{O}$ on a $\mathrm{MgO}$ template is demonstrated.
\end{abstract}

\section{INTRODUCTION}

Copper Oxide $\left(\mathrm{Cu}_{2} \mathrm{O}\right)$ was the first semiconductor material discovered, but was soon overtaken by the fast development of silicon. Nearly 90 years after its discovery, interest in this material has renewed for use in thin film photovoltaics, as there has been much scientific progress in the development and growth of thin films. Previous work conducted on thin film photovoltaics and heterojunctions such as CIGS and CdTe has guided our investigations of $\mathrm{Cu}_{2} \mathrm{O}$. Copper Oxide is a non toxic semiconductor that has a direct band gap of $2.17 \mathrm{eV}$, which is ideal for use in multijunction cells or for photo-electrolysis of water.[1] It also has long minority carrier diffusion length $(\sim 10 \mu \mathrm{m})[2]$. Most importantly it is composed of both earth abundant and inexpensive materials which makes the terawatt scalability of quite feasible especially if photovoltaics will play a large role in the transformation of energy from fossil fuels to solar cells.[3] Copper Oxide is intrinsically a p-type semiconductor predominately due to copper vacancies, and nearly all efforts to form homojunctions by $n$-doping of $\mathrm{Cu}_{2} \mathrm{O}$ have failed. An exception is a recent report [4] in which very preliminary work was reported and no photovoltaic properties were observed. For that reason photovoltaic devices employing $\mathrm{Cu}_{2} \mathrm{O}$ either use Schottky barriers or semiconductor heterojunctions as a mean for charge carrier separation. For the purposes of this paper we use $\mathrm{n}-\mathrm{ZnO}$ as the heterojunction partner in the devices we model and describe.

There are many reports on $\mathrm{Cu}_{2} \mathrm{O}$ solar cells prepared by various techniques including electrodeposition, thermal oxidation of sheet metal, and sputtering deposition. $[3,5,6]$ However, these cells have only reached energy efficiencies that are a fraction of the Shockley-Queisser theoretical value. Despite the effort of many researchers, $p-n$ heterojunctions have yet to demonstrate good performance. Additionally the control of thin film growth and properties has not been well investigated. The lack of high quality material has resulted only in a record efficiency of $2 \%$. [7] We investigate the growth of $\mathrm{MBE} \mathrm{Cu}_{2} \mathrm{O}$ in order to better understand and control material properties of our thin film, in the hopes of ultimately increasing the efficiencies of films fabricated in the future.

\section{MODELING}

\section{Detailed Balance}

To realize the potential of $\mathrm{Cu}_{2} \mathrm{O}$ as both a single junction and multijunction solar cell material, it is important to explore the detailed balance thermodynamic efficiency model of single, double and triple junction solar cells. The standard AM 1.5 solar spectrum is used to determine the thermodynamic efficiency of $\mathrm{Cu}_{2} \mathrm{O}$ at $300 \mathrm{~K}$ under 1 sun concentration. The efficiency of a solar cell is calculated by diving the extracted power from the cell by the integrated power of the AM 1.5 solar spectrum on the cell.

$$
\eta=\frac{J(V) \cdot V}{P}
$$

$J(V)$ is the current density generated by the cell as a function of operating voltage $V$. This model also makes several basic assumptions. These assumptions are that all photons greater than $E_{g}$ are absorbed by the cell and create electron-hole pairs, all recombination occurs radiatively and they are non-thermal, and all absorbed photons equal the number of photons reemitted through radiative recombination plus electron-hole pairs extracted from the cell. The model also takes into account the critical 
angle for emission to a medium of different refractive index. Using the geometry of a thin single-heterojunction on reflective back surface contact the efficiency is determined to be $18.74 \%$. It is important to note that the distribution of power in the solar spectrum is broad, and it cannot be efficiently harnessed using a single band gap cell. Because the dominant sources of loss are photons with energies either greater than or less than the band gap, multijunction cells are used to more efficiently absorb the broad solar spectrum. Using $\mathrm{Cu}_{2} \mathrm{O}$ as the top cell in both two and three junction cells, it is determined that the optimal lower cell band gap in a 2-junction cell was 1.58 eV resulting in an overall efficiency of $34.21 \%$. In a 3junction cell the optimal bad gaps for the lower cells are determined to be $1.69 \mathrm{eV}$ and $1.35 \mathrm{eV}$ with an overall efficiency of $45.76 \%$. It is important to note that all the modeled cells are current matched and running them in parallel would offer larger efficiencies.

The numbers calculated above are for ideal systems with ideal band gaps, but it is important to look at current material systems being produced to see if any of these cells will gain from being paired with $\mathrm{Cu}_{2} \mathrm{O}$. Using the same assumptions in the single junction model above, efficiencies of $\mathrm{Cu}_{2} \mathrm{O} / \mathrm{Si}$ and $\mathrm{Cu}_{2} \mathrm{O} / \mathrm{GaAs}$ dual junction solar cells are determined to be $27.11 \%$ and $30.08 \%$ respectively.

\section{Device Physics Model}

The device physics model of a $\mathrm{Cu}_{2} \mathrm{O} / \mathrm{ZnO}$ (Fig 1) heterojunction cell will also allow one to gain a better understating of the band structure, and to model cell performance under AM 1.5 illumination. Afors-Het (v 2.2) [8], a heterojunction device physics program developed for a-Si, is used in modeling the solar cell and calculating numerical results.

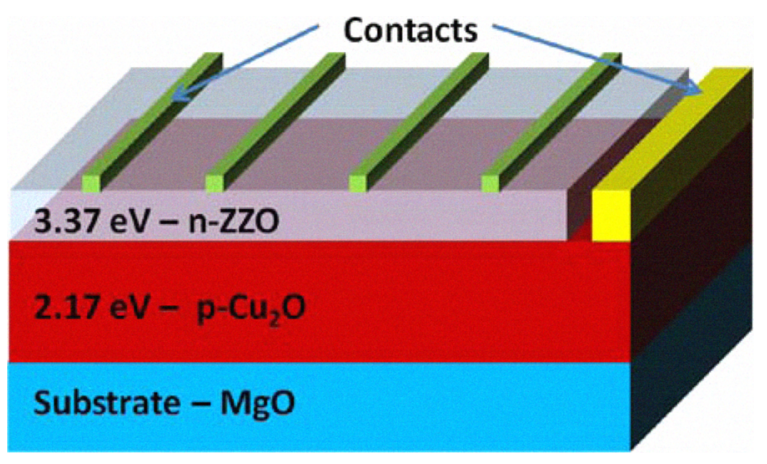

Fig. 1) Schematic of $\mathrm{Cu}_{2} \mathrm{O} / \mathrm{ZnO}$ solar cell.

As expected, the cell is most efficient with no traps or interface defects between the $\mathrm{n}-\mathrm{ZnO} / \mathrm{p}-\mathrm{Cu}_{2} \mathrm{O}$, and the efficiency drops as the concentration of these defects are increased. These simulations assume Lambert-Beer's law of absorption of light and are modeled as closely as possible to materials that have currently been fabricated to date. Optical and electronic of films fabricated in lab are utilized in the simulation. The fabrication of these films will be described in the following section. Figure 2a shows the band diagram of a cell under AM 1.5 illumination. The simulated cell has a $\mathrm{ZnO}$ layer that is $200 \mathrm{~nm}$ thick and a $\mathrm{Cu}_{2} \mathrm{O}$ that is $1 \mu \mathrm{m}$ thick. The band offsets are determined by the electron affinity of the two heterojunction materials. The $\mathrm{Cu}_{2} \mathrm{O}$ layer has an intrinsic carrier concentration of $5 \times 10^{16}$ and the $\mathrm{ZnO}$ layer is almost degenerately doped $\mathrm{Zn}-\mathrm{ZnO}$. Figure $2 \mathrm{~b}, \mathrm{c}$ shows cell performance under $\mathrm{AM}$ 1.5 illumination. The slightly low short circuit currents can be attributed to defect and interface recombination. The high Voc's are encouraging as many heterojunctions fabricated previously have Voc's a fraction (20\%) of these values. The fill factors are strongly dependent on the series resistance of the cells and can greatly vary depending on the doping and mobility of thin film layers as well as contact resistance which is not taken into account in these simulations. The external quantum efficiency calculated for the carrier concentration of $5 \times 10^{16}$ is as expected. The higher values both in Voc and QE can be attributed to modeling a higher quality interface that is possible to be fabricated using MBE.

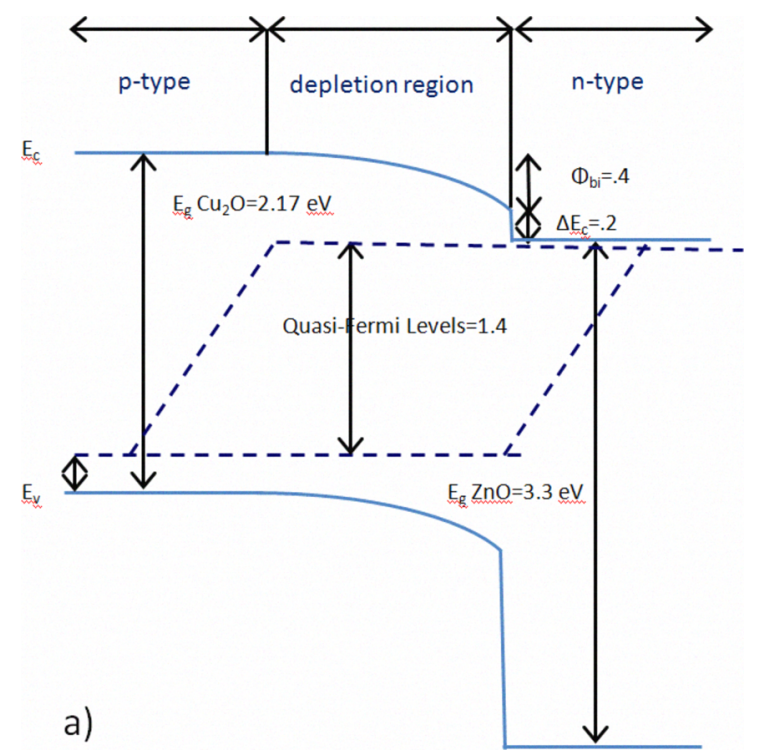



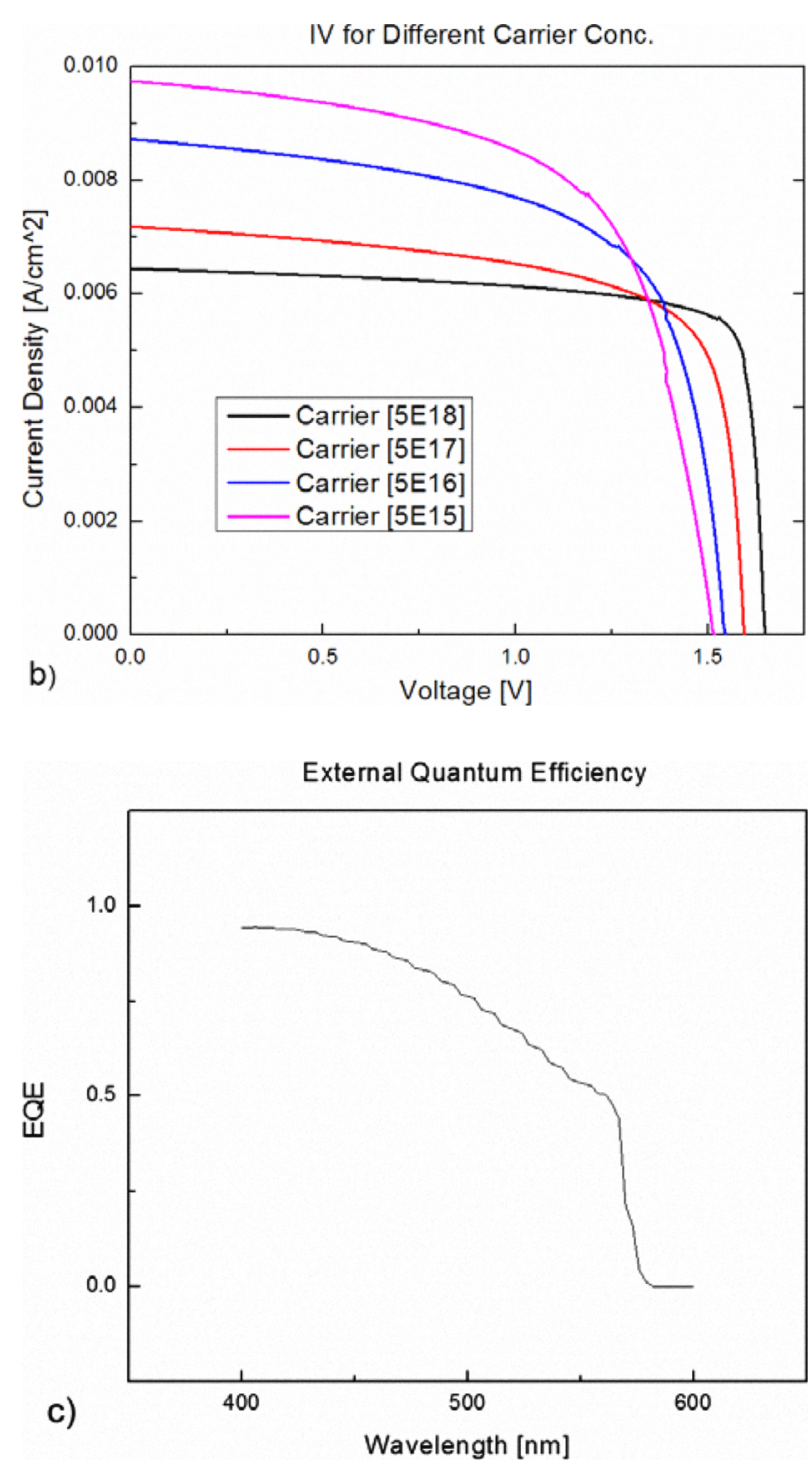

Fig. 2.a) Band diagram of $\mathrm{ZnO} / \mathrm{Cu}_{2} \mathrm{O}$ heterojunction under AM1.5 illumination.b) IV Curves of cells with different carrier concentration for $\mathrm{Cu}_{2} \mathrm{O}$ layer under $\mathrm{AM} 1.5$ illumination. c) EQE of cell with carrier concentration of $5 \times 10^{16}$ under AM 1.5 illumination.

\section{EXPERIMENT}

From the insight that was gained from modeling, Molecular Beam Epitaxy (MBE) seemed to be the best method to fabricate the solar cells, as it provides the greatest control over critical growth conditions such as temperature, flux, base pressure, and interface sharpness. We used cubic Magnesium Oxide (MgO (100), a=4.22 $\AA$ ) as our substrate with a low lattice mismatch of $1.1 \%$ between $\mathrm{Cu}_{2} \mathrm{O}(\mathrm{a}=4.27 \AA)$ and the substrate. We used a copper effusion cell operating through a temperature range $\mathrm{T}=1050^{\circ} \mathrm{C}-\mathrm{T}=1080^{\circ} \mathrm{C}$ and oxygen partial pressure $10^{-4}-10^{-6}$. By varying the oxygen partial pressure and copper effusion rate, we were able to change properties of the film including doping. The optimal conditions were determined to be $\mathrm{T}=1060^{\circ} \mathrm{C}$ for the Knudsen Copper effusion cell, with a substrate temperature of $\mathrm{T}=650^{\circ} \mathrm{C}$. The thin films were grown in the presence of a RF oxygen plasma $(P=300 \mathrm{~W})$ at $10^{-6}$ torr. Several different post deposition annealing steps were explored to create the highest quality film. In-situ characterization of our film was done with Reflective High Energy Electron Diffraction (RHEED). Further analysis was done via $x$-ray diffraction and EDS to confirm the material grown and crystallinity, as well as Hall measurements to obtain the electrical properties of our film.

\section{RESULTS}

$\mathrm{Cu}_{2} \mathrm{O}$ is one of two $\mathrm{Cu} / \mathrm{O}$ stoichiometries.

Because of this it was very important to control the growth of the film; especially the flux of $\mathrm{Cu}$ and $\mathrm{O}$. An active Oxygen plasma allowed the film to grow at a much lower pressure by making the more reactive atomic oxygen available instead of molecular oxygen. As mentioned previously, $\mathrm{MgO}$ was used as the growth substrate. Both the substrate and $\mathrm{Cu}_{2} \mathrm{O}$ have a cubic crystal structure and closely matched lattice parameters. We observed that cube on cube epitaxial $\mathrm{Cu}_{2} \mathrm{O}$ was grown on the $\mathrm{MgO}$ substrate. In-situ RHEED was used to confirm the epitaxial growth, which can be seen in Figure 3. RHEED

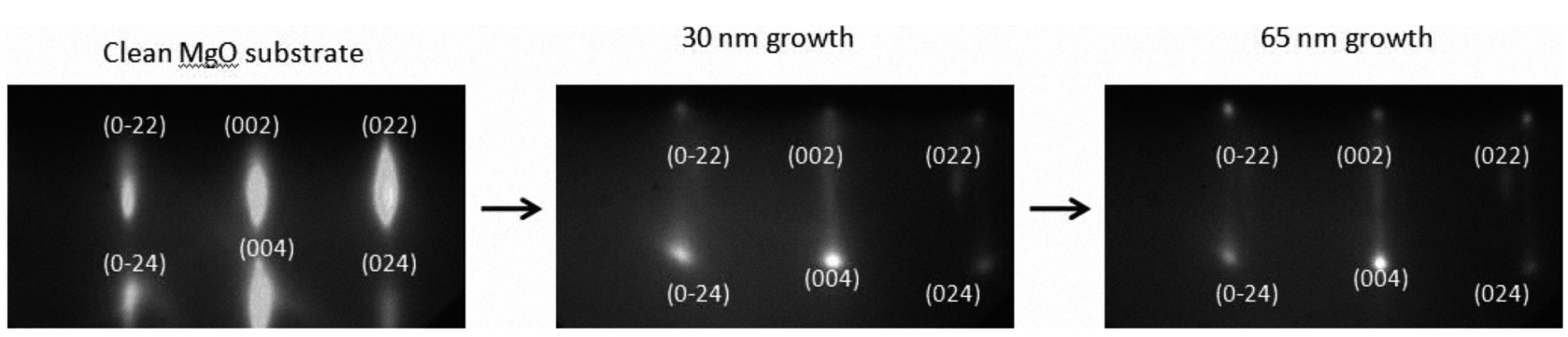

Fig. 3) In-situ RHEED images of epitaxial $\mathrm{Cu}_{2} \mathrm{O}$ on $\mathrm{MgO}$ bulk substrate with diffraction spots indexed. 
oscillations were observed, indicating that the thin film was growing in a layer-by-layer growth regime, typically seen if growth of the film can be well controlled and grown slowly (approximately .2 $\AA / \mathrm{sec}$ ). In addition, the streaky nature of the RHEED image indicated that the film is very smooth. $X$-ray diffraction was conducted on the thin film samples post growth to confirm epitaxy as well as $\mathrm{X}$-ray diffraction of $\mathrm{Cu}_{2} \mathrm{O}$ on $\mathrm{MgO}$ to determine the stoichiometery of the film.

$x$-ray diffraction

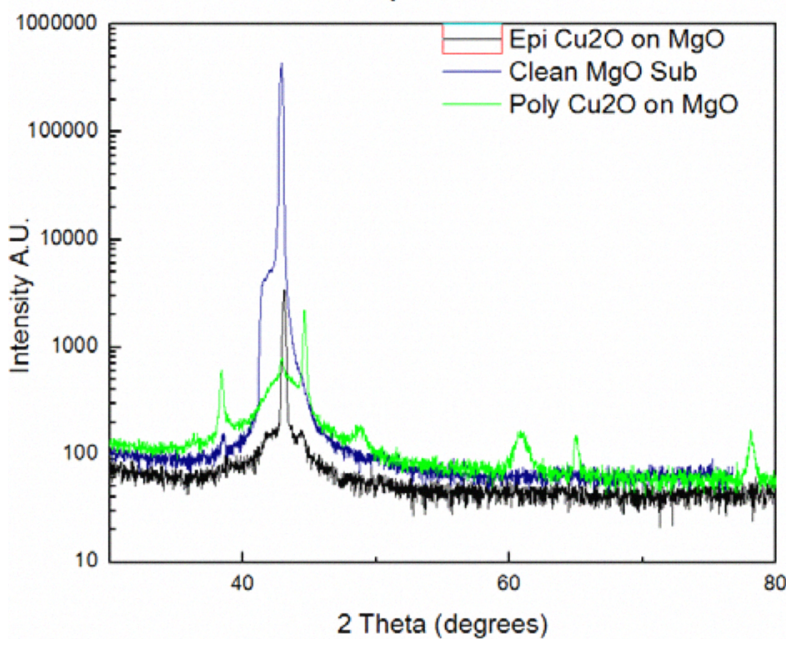

Fig. 4) x-ray diffraction of $\mathrm{Cu}_{2} \mathrm{O}$ on $\mathrm{MgO}$ Sub.

Energy Dispersive X-ray Spectroscopy further confirmed the composition of the film and did not indicate impurities in the film. Hall mobility measurements showed mobilites in the range of $10-100 \mathrm{~cm}^{2} \mathrm{~N}^{*} \mathrm{sec}$ and carrier concentrations in the range of $10^{14}-10^{17}$, which is dependent on substrate temperature and oxygen plasma partial pressure. A very smooth film and the ability of insitu passivation of our interface will hopefully provide the quality interface needed to achieve much higher cell efficiencies. Optical ellipsometery was conducted on the films to determine index of refraction and absorption (see Fig 5). The data measured was subsequently used on other samples to verify film thicknesses and quality post growth.

Very thin template layers on the order of $15-30$ $\mathrm{nm}$ of $\mathrm{MgO}(100)$ were also grown using lon Beam Assisted Deposition (IBAD) on cheap and amorphous substrates. IBAD e-beam $\mathrm{MgO}$ was deposited on top of Silicon Nitride and other cheap substrates, thus eliminating the need of using costly $\mathrm{MgO}$ substrates. In addition, because the template is thin, the resulting film that is grown on top will be less strained and consequently

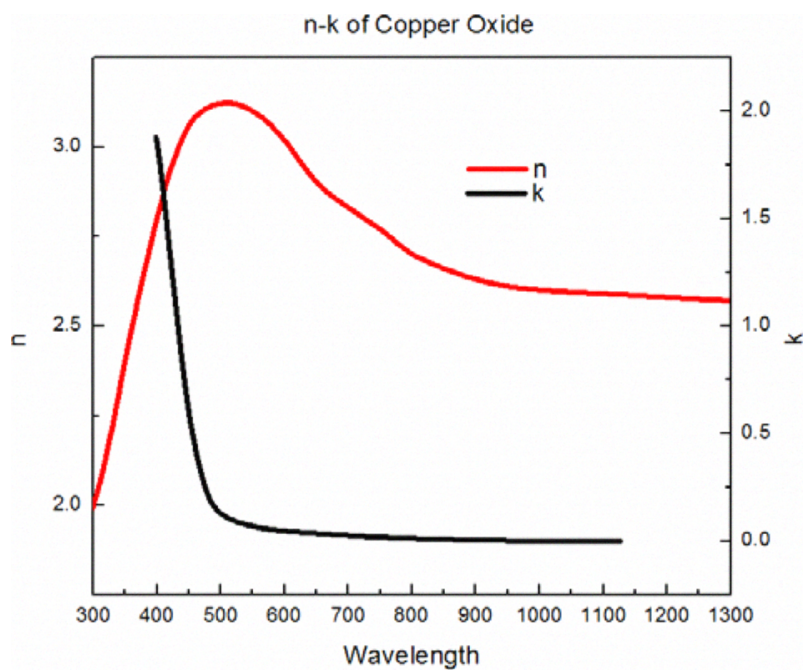

Fig. 5) Measured n-k optical data for $\mathrm{Cu}_{2} \mathrm{O}$ using spectroscopic ellipsometery.

will be of higher quality. As discussed earlier in the modeling section of this paper, the advantage of $\mathrm{Cu}_{2} \mathrm{O}$ solar cells may be used in multijunction tandem cells. IBAD MgO can significantly lower the cost of the overall cell, and makes it convenient to integrate with existing cells as several commercial cells on the market today use $\mathrm{Si}_{3} \mathrm{~N}$ emitter layers thus making growth of our $\mathrm{Cu}_{2} \mathrm{O}$ cell on top of existing cells fairly easy. Figure 6 shows RHEED images of IBAD MgO grown on an amorphous $\mathrm{SiO}_{2}$ layer. Subsequent epitaxial deposition of $\mathrm{Cu}_{2} \mathrm{O}$ was observed.

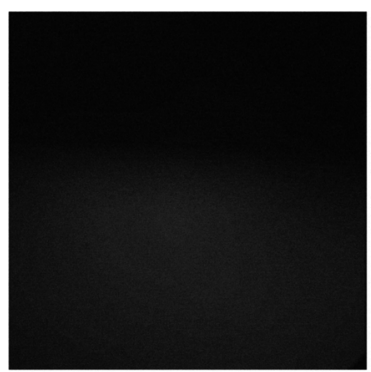

onm $\mathrm{MgO}-\mathrm{SiO}_{2} \mathrm{Sub}$

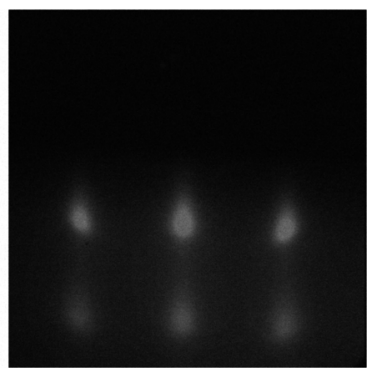

$15 \mathrm{~nm} \mathrm{MgO}-\mathrm{SiO}_{2} \mathrm{Sub}$

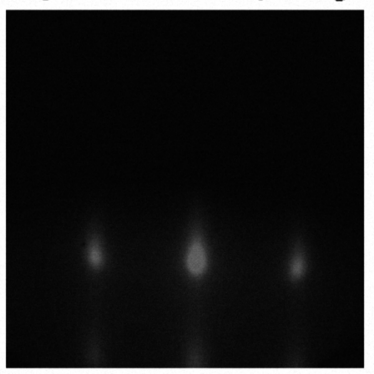

$15 \mathrm{nmCu}_{2} \mathrm{O} / 15 \mathrm{~nm} \mathrm{MgO}-\mathrm{SiO}_{2} \mathrm{Sub}$

Fig. 6) $\mathrm{Cu}_{2} \mathrm{O} / \mathrm{BBAD} \mathrm{MgO}$ grown on $\mathrm{SiO}_{2}$. 


\section{CONCLUSION}

A thermodynamic detailed balance model was used to obtain ultimate efficiencies of both single and multijunction solar cells made with a $\mathrm{Cu}_{2} \mathrm{O} / \mathrm{ZnO}$ heterojunction. The most efficient band gaps were also determined for multijunction cells under AM 1.5 illumination. The device physics model of the $\mathrm{Cu}_{2} \mathrm{O}$ cell explored the effects of material quality, surface, and interface quality as well as identifying the target electrical properties the films should have. Current solar cell technologies on the market were also considered for use in $\mathrm{Cu}_{2} \mathrm{O}$ multijunction tandem cells. These tandem cell combination detailed balance thermodynamic efficiencies were also calculated. $\mathrm{MBE}$ growth of epitaxial $\mathrm{Cu}_{2} \mathrm{O}$ was demonstrated on (100) MgO. Structural and electrical qualities of the film were characterized using RHEED, $x-$ ray diffraction, EDS, and Hall mobility measurements. Further characterization of material quality via PL lifetime and TEM are underway and will be reported in the future in order to help characterize quality of our material and junctions.

\section{ACKNOWLEDGEMENTS}

We acknowledge financial support from U.S. Department of Energy under grant DE-FG36-08G018006, and the Caltech Center for Sustainable Energy Research. We thank Dr. Matthew Dicken, Greg Kimball, and Carrie Hofmann for engaging discussions and assistance.

\section{REFRENCES}

[1] Minami, Tadatsugu et al., "Effect of $\mathrm{ZnO}$ film deposition methods on the photovoltaic properties of $\mathrm{ZnO}-$ $\mathrm{Cu}_{2} \mathrm{O}$ heterojunction devices", Thin Solid Films. 494, 2006, pp 47

[2] Olsen, L. C., Quarterly Progress Report, 1 Nov. 1979 31 Jan. 1980 Joint Center for Graduate Study, Richland, WA

[3] A. Parreta, "Polycrystalline $\mathrm{n}-\mathrm{ZnO} / \mathrm{p}-\mathrm{Cu}_{2} \mathrm{O}$ heterojunctions grown by RF-magnetron sputtering", Phys. Stat. Sol. (a) 155, 1996, pp 399

[4] L. Wang, M. Tao, "Electrochemically deposited p-n homojunction cuprous oxide solar cell”, Electrochem. Solid-State Lett. 10, 2007, pp 153
[5] J. Katayama et. al., "Performance of $\mathrm{Cu}_{2} \mathrm{O} / \mathrm{ZnO}$ solar cell prepared by two-step electrodeposition", Journal of Applied Electrochemistry 34, 2004, pp 687

[6] Nobuko Naka, et. al., "Thin Films of Single-Crystal Cuprous Oxide Grown from the Melt", Japanese Joumal of Applied Physics, 44, No. 7A, 2005, pp. 5096

[7] Alberto Mittiga, et. al., "Heterojunction solar cell with $2 \%$ efficiency based on a $\mathrm{Cu}_{2} \mathrm{O}$ substrate", Appl. Phys. Lett, 88, 2006,pp 163502

[8] R. Stangl, M. Kriegel, M. Schmidt, "AFORS-HET, Version 2.2" 